\title{
他念他翁山中段第四纪冰川沉积物 时空分布特征与环境
}

\author{
张 威, 唐倩玉 \\ (辽宁师范大学城市与环境学院, 辽宁大连 116029)
}

\begin{abstract}
摘 要: 他念他翁山中段位于横断山脉西部, 保留着良好的第四纪冰川遗迹, 论文以该地区第四纪冰川沉积物为主 要研究对象, 通过光释光(Object-source lighting, OSL)测年、粒度、磁化率、矿物及化学元素分析等方法, 探讨研究区 第四纪冰川沉积物在不同时期的沉积学、矿物学、环境磁学以及元素地球化学特征,结合相关环境指标分析该区的 环境特点。研究表明: (1) 冰川沉积物总体沉积特征是大小混杂、无层理、无分选、风化程度由倒数第二次冰期到新 冰期依次减弱。(2) 研究区冰川沉积物细粒部分在粒度频率曲线上主要呈现双峰或多峰, 反映出沉积物的物质来 源复杂、形成动力多样。冰碛物的平均粒径在空间上表现出距冰川作用源头越远粒径越小的规律, 主要是受冰川 作用强度和风化时间长短的影响。(3) 冰川沉积物的磁化率值为 $8.72 \times 10^{-8} \sim 298.00 \times 10^{-8} \mathrm{~m}^{3} \cdot \mathrm{kg}^{-1}$, 其中冰水沉积物磁 化率的平均值 $\left(178.51 \times 10^{-8} \mathrm{~m}^{3} \cdot \mathrm{kg}^{-1}\right)$ 和波动幅度 $\left(17.43 \times 10^{-8} \sim 298.00 \times 10^{-8} \mathrm{~m}^{3} \cdot \mathrm{kg}^{-1}\right.$ ) 要大于冰碛物 (平均值 $19.82 \times 10^{-8}$ $\mathrm{m}^{3} \cdot \mathrm{kg}^{-1}$, 波动幅度 $\left.8.72 \times 10^{-8} \sim 42.95 \times 10^{-8} \mathrm{~m}^{3} \cdot \mathrm{kg}^{-1}\right)$, 反映出磁铁矿集中分布的粒级与冰水沉积物组成的粒级相似。 (4) 地球化学和矿物学指标反映青古隆地区古气候的总体特征为寒冷干燥, 其中在末次冰盛期时气候最为干旱, 末 次冰期中冰阶时气候较为干旱、降水量相对于末次冰盛期有所增加, 倒数第二次冰期降水量相对于末次冰盛期和 末次冰期中冰阶较多, 但气温较低。
\end{abstract}

关 键 词: 光释光测年; 粒度; 磁化率; 化学元素; 矿物学; 冰川沉积物; 他念他翁山中段

第四纪冰川沉积物是恢复特定时段环境特征 的重要替代指标之一, 以往对第四纪冰川沉积物的 研究主要是进行冰期系列划分, 重点关注冰碛物的 宏观地貌与微观结构组成, 在宏观沉积地貌方面, 重点是冰碛物的垄状地形(侧碛垄、终碛垄、中碛垄 等)(康建成, 1989; 崔之久等, 1999; 胡恩等, 2010; 陈 仁容等, 2012) 以及沉积物的风化特征(李亚兵等, 2006), 而微观方面则重点研究冰碛物的岩性组成、 矿物学特点、元素地球化学组成、粒度分布特征、沉 积物颗粒的微结构等方面, 在方法上也多基于传统 的元素地球化学(王立伦等, 1989; 刘耕年等, 2009)、 沉积学(崔之久等, 1994; Evans et al, 2010; 陈安东 等, 2016)、矿物学(Jacobson et al, 2002; Krylov et al, 2008)、生物学(唐领余等, 1983; 刘雯雯等, 2015)等 分析方法。近年来, 随着研究与分析手段的不断进
步, 一些新的环境变化指标被引入第四纪研究领 域, 如对冰川沉积物环境磁学特征的测试与分析 (张威等, 2012)、反映化学风化强度的化学蚀变指数 (chemical index of alteration, CIA) 的运用以及冰川 沉积物粘土矿物分析(张子洋等, 2017)等, 有力地推 动了区域环境分析方面的研究工作。

他念他翁山中段位于横断山脉西部, 保留着良 好的第四纪冰川遗迹, 为恢复西南季风区第四纪冰 川演化过程及其环境背景提供了良好的物质基础, 然而, 该区的第四纪冰川沉积与地貌特征研究比较 薄弱。最近几年,在国家自然科学基金项目的支持 下,笔者对他念他翁山中段的第四纪冰川地貌进行 考察, 并对冰期系列进行了初步划分(张威, 柴乐, 2016)。本文即是在前期考察结果的基础上,采用 多种环境变化替代指标, 对研究区不同时空条件下

收稿日期: 2018-10-26; 修订日期: 2019-01-08。

基金项目:国家自然科学基金项目(41671005)。[Foundation: National Natural Science Foundation of China, No. 41671005. ]

第一作者简介: 张威(1969-), 男,吉林松原人,教授,博士, 从事环境与灾害地貌研究。E-mail: zhangweilnu@163.com Geography, 38(6): 904-917. ] DOI: 10.18306/dlkxjz.2019.06.011 
的第四纪冰川沉积物特征进行深人分析, 探讨该地 区不同时期气候环境的演变特点。

\section{1 研究区概况}

他念他翁山中段位于西藏自治区东北部, 属于 青藏高原东缘山地, 是青藏高原和云贵高原的过渡 地带, 山体大体呈 NW-SE走向分布,海拔在 3900 $5900 \mathrm{~m}$ 左右(图 1), 该地区的现代雪线在 $5400 \mathrm{~m}$ 左 右(张威, 柴乐, 2016), 第四纪冰川遗迹广布, 冰川形 态类型主要以冰斗冰川、悬冰川为主,共有现代冰 川346条(苏珍等, 1966), 第四纪冰川侵蚀地貌如冰 斗、 $U$ 型谷、冰坎等和堆积地貌如侧碛垄、终碛垄等 发育。如图 1 所示, 研究区沿着玉曲流域从东南向 西北依次是 4 号槽谷(简称 4 号槽, 下同)、 5 号槽谷、6 号槽谷、觉曲和如曲谷地, 范围在 $96^{\circ} 20^{\prime} \mathrm{E} \sim 97^{\circ} 60^{\prime}$ $\mathrm{E}, 30^{\circ} 0^{\prime} \mathrm{N} \sim 31^{\circ} 0^{\prime} \mathrm{N}$, 研究区岩石类型以三叠系的 砂岩、粉砂岩、灰岩、板岩, 泥盆系的千枚岩、变质 岩、板岩, 侏罗系的二长花岗岩、紫红色的砂岩、页 岩、砾岩为主(陈福忠等, 1983)。
该地区属于高原亚温带亚湿润气候, 冬季降水 稀少、气候寒冷, 夏季在西南季风的控制下, 降水相 对充沛, 气候温和湿润, 年降水量在 $500 \mathrm{~mm}$ 左右, 1 月份平均气温 $-2.5^{\circ} \mathrm{C}, 7$ 月份平均气温 $16.3^{\circ} \mathrm{C}$, 年平 均气温 $7.6{ }^{\circ} \mathrm{C}$ (高由禧等, 1984)。近 $40 \mathrm{a}$ 冬季气温呈 上升趋势, 这是年平均气温升高并导致近年来冰川 后退的主要原因。

\section{2 材料与方法}

\section{1 冰碛物分布与采样剖面}

研究区共采集 20 个冰川沉积物样品以及 3 个 光释光(Object-source lighting, OSL)样品。其中: BD-01、BD-02、BD-03、BD-04 和 OSL-04、OSL-05、 OSL-06采自 4 号槽的二套冰碛物, BD-05 采自第三 套冰碛物, BD-06、BD-07、BD-08 采自 6 号槽的第四 套冰碛物。

RQ-01、RQ-02 和 RQ-03 采自如曲谷地距离冰斗 后壁 $2 \mathrm{~km}$ 处岩坎处第一套冰碛垄, RQ-04采自距离冰 斗 $5 \mathrm{~km}$ 的第二套冰碛物, RQ-05 采自距冰斗处约 11

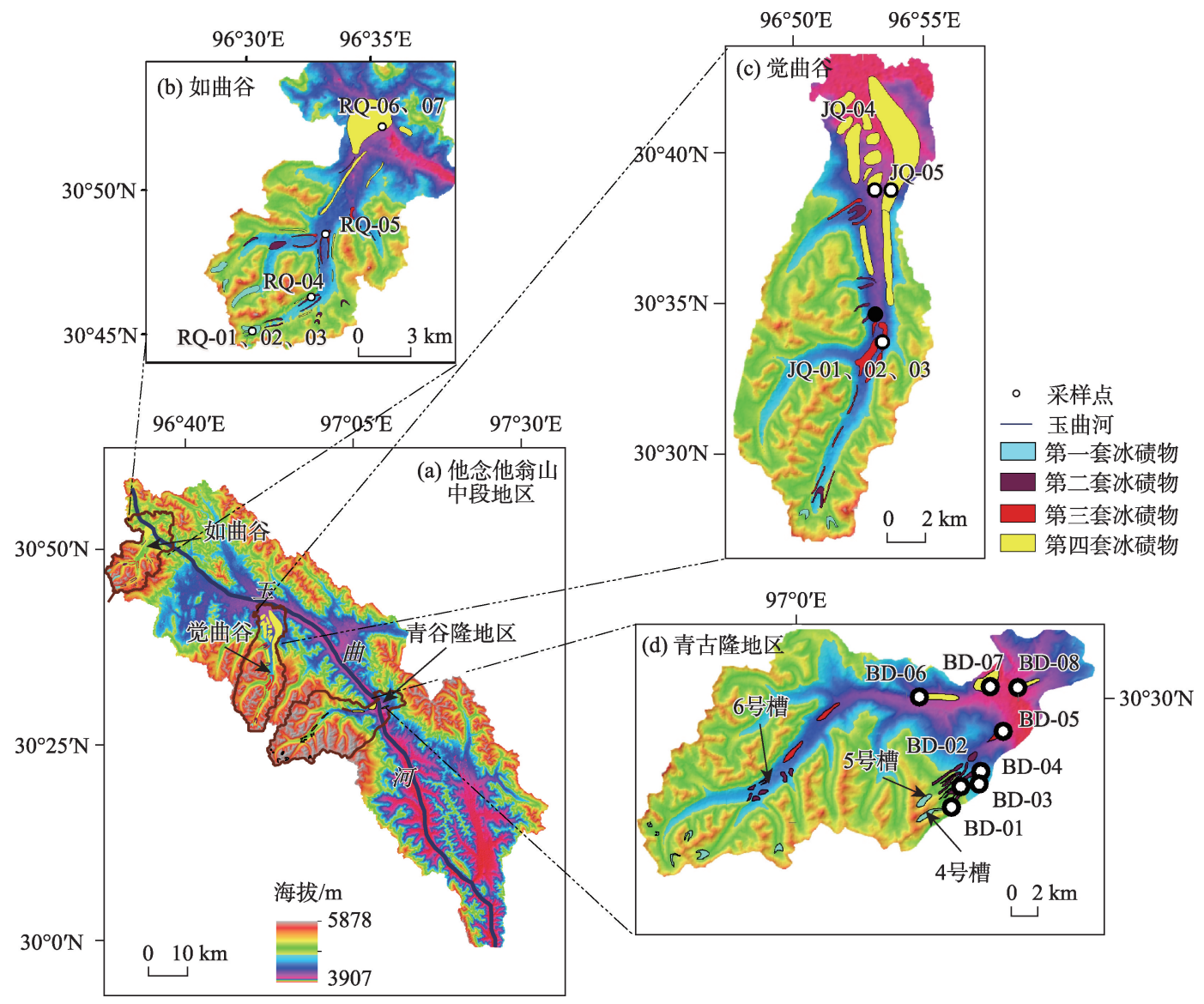

图 1 他念他翁山中段地区冰川沉积物采样点分布

Fig.1 Sampling sites of glacier deposits in the middle Tenasserim Chain 
$\mathrm{km}$ 的第三套冰碛物, RQ-06 和 RQ-07采自距离冰斗 源头约 $25 \mathrm{~km}$ 的第四套冰碛物末端。

$J Q-01 、 J Q-02$ 和 JQ-03 采自觉曲谷地第三套冰 碛物, JQ-04、JQ-05 采自第四套冰碛物。详细的采
样信息见图 1、图 2 和表 1 。

\section{2 实验方法}

将样品自然风干和用孔径 $2 \mathrm{~mm}$ 的耖子进行篮 选后,在华南师范大学光释光实验室对冰川沉积物

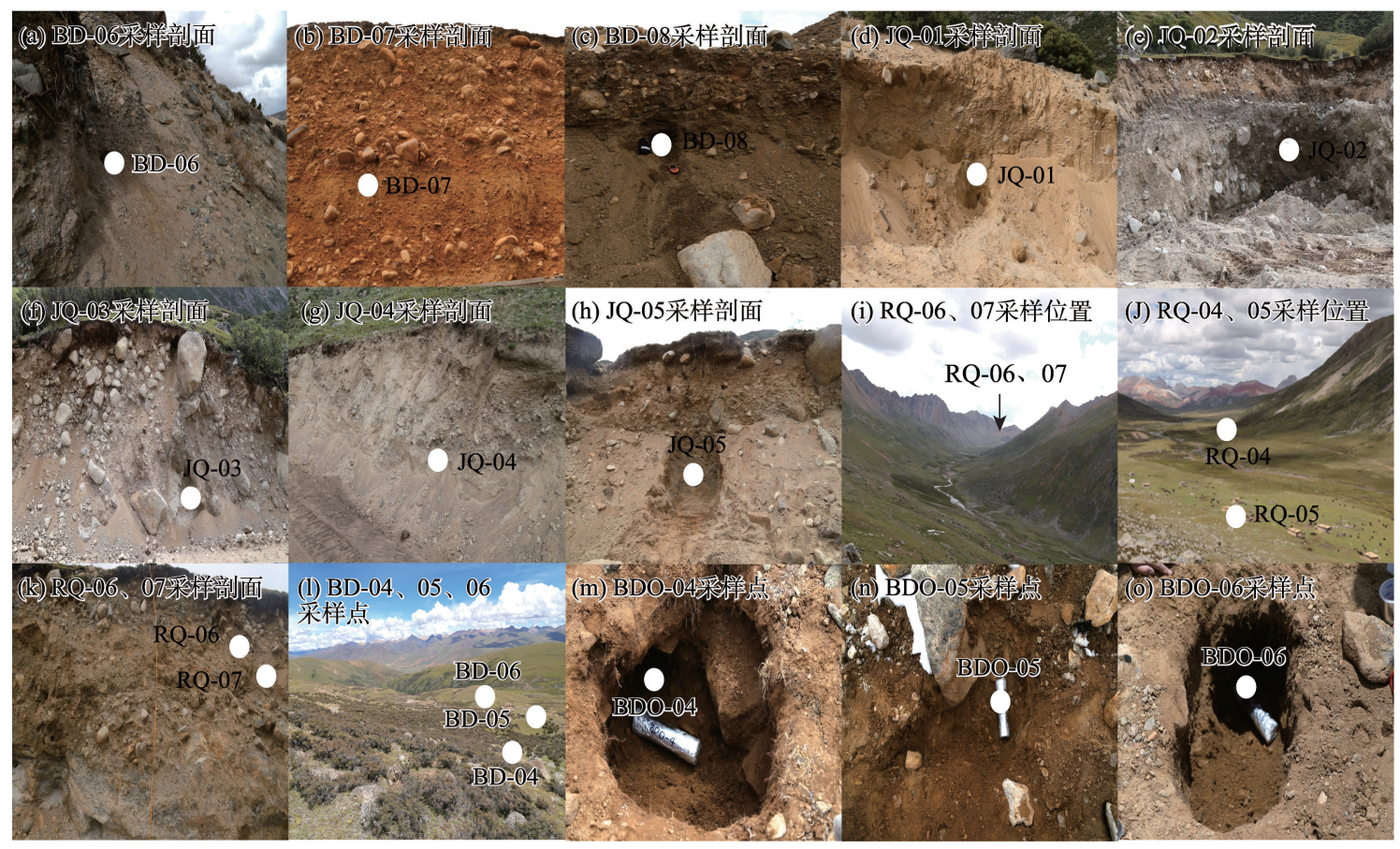

图 2 冰川沉积物剖面采样点位置分布示意图

Fig.2 Distribution of the sampling points of the glacier deposits

表 1 他念他翁山冰川沉积物样品采样地点及信息

Tab.1 Sampling sites and information of the sampling points of the glacier deposits

\begin{tabular}{|c|c|c|c|c|c|}
\hline 样品编号 & 经度/E & 纬度/N & 海拔/m & 深度 $/ \mathrm{m}$ & 沉积物性质 \\
\hline RQ-01 & $96^{\circ} 30^{\prime} 12.27^{\prime \prime}$ & $30^{\circ} 45^{\prime} 01.27^{\prime \prime}$ & 5096 & 1.0 & 冰碛物 \\
\hline RQ-02 & $96^{\circ} 30^{\prime} 19.58^{\prime \prime}$ & $30^{\circ} 45^{\prime} 03.77^{\prime \prime}$ & 5081 & 0.8 & 冰碛物 \\
\hline RQ-03 & $96^{\circ} 30^{\prime} 42.23^{\prime \prime}$ & $30^{\circ} 45^{\prime} 11.66^{\prime \prime}$ & 5016 & 0.6 & 冰碛物 \\
\hline RQ-04 & $96^{\circ} 32^{\prime} 36.76^{\prime \prime}$ & $30^{\circ} 46^{\prime} 12.61^{\prime \prime}$ & 4910 & 0.5 & 冰碛物 \\
\hline RQ-05 & $96^{\circ} 33^{\prime} 10.48^{\prime \prime}$ & $30^{\circ} 48^{\prime} 17.48^{\prime \prime}$ & 4770 & 0.5 & 冰碛物 \\
\hline RQ-06 & $96^{\circ} 35^{\prime} 17.63^{\prime \prime}$ & $30^{\circ} 52^{\prime} 14.01^{\prime \prime}$ & 4662 & 1.1 & 冰碛物 \\
\hline BD-01 & $97^{\circ} 07^{\prime} 07.72^{\prime \prime}$ & $30^{\circ} 25^{\prime} 45.91^{\prime \prime}$ & 5243 & 0.9 & 冰碛物 \\
\hline BD-02 & $97^{\circ} 07^{\prime} 24.75^{\prime \prime}$ & $30^{\circ} 26^{\prime} 32.76^{\prime \prime}$ & 5010 & 1.1 & 冰碛物 \\
\hline BD-03 & $97^{\circ} 08^{\prime} 20.17^{\prime \prime}$ & $30^{\circ} 26^{\prime} 41.32^{\prime \prime}$ & 4809 & 1.2 & 冰碛物 \\
\hline BD-04 & $97^{\circ} 08^{\prime} 23.16^{\prime \prime}$ & $30^{\circ} 27^{\prime} 12.43^{\prime \prime}$ & 4682 & 0.8 & 冰碛物 \\
\hline BD-05 & $97^{\circ} 09^{\prime} 20.53^{\prime \prime}$ & $30^{\circ} 28^{\prime} 48.01^{\prime \prime}$ & 4405 & 1.3 & 冰碛物 \\
\hline BD-07 & $97^{\circ} 08^{\prime} 46.41^{\prime \prime}$ & $30^{\circ} 30^{\prime} 27.79^{\prime \prime}$ & 4330 & 1.5 & 冰碛物 \\
\hline RQ-07 & $96^{\circ} 36^{\prime} 11.50^{\prime \prime}$ & $30^{\circ} 51^{\prime} 52.96^{\prime \prime}$ & 4596 & 2.1 & 冰水沉积物 \\
\hline JQ-01 & $96^{\circ} 53^{\prime} 32.96^{\prime \prime}$ & $30^{\circ} 34^{\prime} 16.35^{\prime \prime}$ & 4598 & 2.5 & 冰水沉积物 \\
\hline JQ-02 & $96^{\circ} 53^{\prime} 36.07^{\prime \prime}$ & $30^{\circ} 34^{\prime} 10.22^{\prime \prime}$ & 4612 & 2.0 & 冰水沉积物 \\
\hline JQ-03 & $96^{\circ} 53^{\prime} 34.33^{\prime \prime}$ & $30^{\circ} 34^{\prime} 16.17^{\prime \prime}$ & 4600 & 1.6 & 冰水沉积物 \\
\hline JQ-04 & $96^{\circ} 53^{\prime} 33.22^{\prime \prime}$ & $30^{\circ} 38^{\prime} 29.00^{\prime \prime}$ & 4525 & 1.7 & 冰水沉积物 \\
\hline JQ-05 & $96^{\circ} 53^{\prime} 19.10^{\prime \prime}$ & $30^{\circ} 38^{\prime} 29.00^{\prime \prime}$ & 4495 & 1.2 & 冰水沉积物 \\
\hline BD-06 & $97^{\circ} 05^{\prime} 31.02^{\prime \prime}$ & $30^{\circ} 29^{\prime} 56.94^{\prime \prime}$ & 4472 & 1.1 & 冰水沉积物 \\
\hline BD-08 & $97^{\circ} 09^{\prime} 58.69^{\prime \prime}$ & $30^{\circ} 30^{\prime} 26.57^{\prime \prime}$ & 4380 & 1.3 & 冰水沉积物 \\
\hline
\end{tabular}


进行光释光年代分析, 在辽宁师范大学沉积学实验 室分别进行粒度、化学元素和磁化率分析, 在中国 地质大学(北京)进行全岩和粘土矿物分析。

光释光测年 : (1) 首先除去粗颗粒, 将细颗粒 $(300 \mu \mathrm{m})$ 依次浸人稀盐酸和过氧化氢中以除去碳酸 盐和有机物。将颗粒再次篮选获得 38 63 $\mu \mathrm{m}$ 的组 分, 将其浸泡在氟硅酸中以除去长石, 然后使用少 量稀盐酸以消除样品的氟化物沉淀。通过 IRSL 扫 描提取的石英颗粒纯度。(2) 将硅胶均匀地涂覆在 直径为 $0.97 \mathrm{~cm}$ 的不锈钢晶片上, 并将样品均匀地 固定在约 $0.67 \mathrm{~cm}$ 的直径内。通过单片再生剂量 (SAR)和标准化生长曲线( $\mathrm{SGC}$ )方法测量等效剂量 (De), 使用热释光/光学刺激的发光读数器。用 $90 \mathrm{Sr} / 90 \mathrm{Y} \beta$ 源进行照射。通过中子活化分析(NAA) 测量 $\mathrm{U}, \mathrm{Th}$ 和 $\mathrm{K}$ 的浓度以计算年剂量。测试含水量 在 $0.59 \%$ 3.8\% 之间。(3) 根据样本的海拔高度、地 理位置和采样深度计算宇宙射线对年剂量的贡献。

粒度分析: (1) 称取 $0.3 \mathrm{~g}$ 样品, 放在烧杯中; (2)向 烧杯中分别加人浓度为 $10 \%$ 的 $\mathrm{H}_{2} \mathrm{O}_{2}$ 和 $\mathrm{HCL}$ 溶液, 直至完全反应; 3 加人蒸馏水静置后, 利用虹吸现 象用胶管吸取表面悬浮的液体, 重复此步骤, 直到 用 $\mathrm{pH}$ 试纸测试为中性; (4) 加人配置好的 $5 \mathrm{~mL}$ 浓度 为 $0.05 \mathrm{~mol} / \mathrm{L}$ 的 $\left(\mathrm{NaPO}_{3}\right)_{6}$ 溶液, 再加 $50 \mathrm{~mL}$ 蒸馏水, 用 LS 13320 激光衍射粒度分析仪震荡 $60 \mathrm{~s}$ 后测试。

化学元素分析: (1) 将样品放人研磨器中, 使用 型号为 SM-1 的振动研磨机研磨, 在 $30 \mathrm{MPa}$ 的压力 下研磨 $30 \mathrm{~s}$ 以上。(2) 取研磨好的样品放人 BP-1 粉 末压样机中, 在 20 30 MPa 的压力下, 制成圆饼状 样片。(3) 将样片放人日本理学公司生产的 X射线 苂光光谱仪中, 进行沉积物常量元素测定, 分析误 差低于 $2 \%$ 。

磁化率分析: (1) 用电子秤称取容积为 $10 \mathrm{~cm}^{3}$ 的 塑料样品空盒的质量为 $m_{1}$; 将样品放人塑料样品空 盒中, 装满压实后进行称重, 质量为 $m_{2}$; 样品质量为 $m=m_{2}-m_{1}$; 此步骤重复进行 3 次, 计算平均值。(2) 用 英国 Bartington公司生产的 MS2 型磁化率仪分别对 样品的磁化率进行测量, 每个样品的低频 $(0.46 \mathrm{kHz})$ 和高频 $(4.6 \mathrm{kHz})$ 容积磁化率分别测试 3 次取平均 值。(3) 样品低频质量磁化率为测量的低频容积磁 化率/密度, 样品高频质量磁化率为测量的高频容积 磁化率/密度, 其中密度等于样品的质量/体积, 样品 频率磁化率为(低频质量磁化率-高频质量磁化率)/ 低频质量磁化率 $\times 100 \%$ 。

全岩矿物分析: 用玛瑙钵将样品研磨后放人载 玻片上, 取毛玻璃片轻压样品表面, 将多余粉末刮 掉, 反复平整样品, 使样品表面压实且不高出载玻 片上样品架平面, 放人 SmartLab 型 X 射线衍射仪测 试,测试后的数据用 Jade 6.0 软件进行分析。

粘土矿物分析: 样品过 200 目的篮子后放人烧 杯中加 $350 \mathrm{~mL}$ 蒸馏水, 然后用电动搅拌器搅拌 7 8 $\min$, 静置 $8 \mathrm{~h}$ 后, 取烧杯中部浑浊液体至试管(约 11 $\mathrm{mL}$ 放人离心机中, 离心后的样品放人载玻片上, 待 自然风干后放人 SmartLab 型 X 射线衍射仪测试,测 试后的数据用 Jade 6.0 软件进行分析。

\section{3 结果分析}

\subsection{OSL 测年结果}

等效剂量和年剂量结果列于表 2 中,结合该区 域冰川沉积物的 ESR 测年结果(张威, 柴乐, 2016), 得出第四纪期间青古隆地区至少发生了 4 次冰川作 用。第一套冰碛物基于相对地貌被确定为来自新 冰期/小冰期, 对应于 MIS1(MIS=Morine 氧同位素 阶段)。第二套冰碛物 OSL-04 (17.3 $\pm 1.25 \mathrm{ka}) 、 O S L$ $05(31.38 \pm 3.48 \mathrm{ka})$ 和 OSL-06 $(25.78 \pm 1.98 \mathrm{ka})$ 的测年 结果与 ESR 测年的结果 $(25 \pm 1 \mathrm{ka} 、 38 \pm 6 \mathrm{ka} 、 26 \pm 4 \mathrm{ka}$ 和 $31 \pm 6 \mathrm{ka}$ )一致,形成于末次冰盛期(MIS2)。第三 套冰碛物上 2 个 ESR 样品年代分别为 $55 \pm 8 \mathrm{ka}$ 和

表 2 OSL 测年结果

Tab.2 Object-source lighting (OSL) dating result

\begin{tabular}{|c|c|c|c|c|c|c|c|c|c|c|c|}
\hline 样品 & $\begin{array}{c}\text { 海拔 } \\
/ \mathrm{m}\end{array}$ & 采样点 & 深度 $/ \mathrm{m}$ & 性质 & $\begin{array}{c}\mathrm{U} \\
/\left(\mathrm{mg} \cdot \mathrm{ka}^{-1}\right)\end{array}$ & $\begin{array}{c}\mathrm{Th} \\
/\left(\mathrm{mg} \cdot \mathrm{ka}^{-1}\right)\end{array}$ & $\mathrm{K} / \%$ & $\begin{array}{c}\text { 含水量 } \\
/ \%\end{array}$ & $\begin{array}{l}\text { 年剂量率 } \\
/\left(\mathrm{GY} \cdot \mathrm{ka}^{-1}\right)\end{array}$ & 等效剂量/GY & 年代/ka \\
\hline OSL-04 & 4644 & $\begin{array}{l}97^{\circ} 08^{\prime} 19.99^{\prime \prime} \mathrm{E} \\
30^{\circ} 27^{\prime} 05.12^{\prime \prime} \mathrm{N}\end{array}$ & 0.65 & 细砂、粉砂 & 2.56 & 12.0 & 1.54 & 0.59 & 3.428 & $59.30 \pm 4.30$ & $17.30 \pm 1.25$ \\
\hline OSL-05 & 4867 & $\begin{array}{l}97^{\circ} 08^{\prime} 04.04^{\prime \prime} \mathrm{E} \\
30^{\circ} 26^{\prime} 35.42^{\prime \prime} \mathrm{N}\end{array}$ & 0.7 & 细砂、粉砂 & 2.80 & 12.9 & 1.47 & 0.93 & 3.476 & $109.06 \pm 12.10$ & $31.38 \pm 3.48$ \\
\hline OSL-06 & 4922 & $\begin{array}{l}97^{\circ} 07^{\prime} 44.36^{\prime \prime} \mathrm{E} \\
30^{\circ} 26^{\prime} 34.54^{\prime \prime} \mathrm{N}\end{array}$ & 1.0 & 细砂、粉砂 & 2.83 & 13.0 & 1.71 & 3.80 & 3.645 & $93.97 \pm 7.20$ & $25.78 \pm 1.98$ \\
\hline
\end{tabular}


$54 \pm 9 \mathrm{ka}$, 确定第三套冰川沉积物形成于 MIS3b 阶 段。第四套冰碛物上 3 个 ESR 样品测年结果为 192 $\pm 51 \mathrm{ka} 、 207 \pm 45 \mathrm{ka}$ 和 $207 \pm 29 \mathrm{ka}$, 对应倒数第二次 冰期(MIS6), 是该地区最早的一次冰川作用。

\section{2 粒度特征}

\subsection{1 粒度组成特征}

激光粒度仪输出的原始数据经伍登-温哥华方 案(Wentworth et al, 1922)分级得出不同粒级的百分 比含量, 并通过福克和沃德样品统计值图解法的计 算公式得出冰川沉积物的平均粒径、标准差、偏度 和峰态(表 3)。他念他翁山中段地区冰川沉积物的 平均粒径 $\left(M_{z}\right)$ 为 $176.78 \mu \mathrm{m}$, 粒级组成以砂级为主 (72.72\%), 其次是粉砂 $(25.29 \%)$ 和粘土 (1.98\%), 冰碛 物的平均粒径为 $145.11 \mu \mathrm{m}$, 砂级含量为 $67.02 \%$, 粉 砂为 $30.35 \%$, 粘土为 $2.63 \%$; 冰水沉积物的平均粒 径为 $224.29 \mu \mathrm{m}$, 砂级为 $81.28 \%$, 粉砂为 $17.71 \%$, 粘 土为 $1.01 \%$ 。标准差 $\left(\sigma_{i}\right)$ 能够反映被测沉积物数据 的分选程度, 当 $\sigma_{i}>2$ 时代表分选很差(李全莲等,
2015), 研究区冰川沉积物标准差平均值为 2.07 , 表 示分选很差。偏度 $\left(S_{k}\right)$ 可以用于判断沉积物粒度频 率分布的对称性(徐树建等, 2014), 研究区冰川沉积 物偏度为 $-0.13 \sim 0.51$, 峰态 $\left(K_{\mathrm{g}}\right)$ 为 $0.78 \sim 1.25$, 符合冰 川沉积物的特点(Zhao et al, 2010)。

当物质来源复杂或有多种动力形成沉积物时, 在频率曲线上会呈现双峰或多峰(刘亮, 2017)。由 研究区内冰川沉积物 $\leqslant 2 \mathrm{~mm}$ 粒径频率分布(图 3)可 以看出 12 个冰碛物样品中只有 1 个样品(RQ-04)多 峰现象不明显, 其余样品均为多峰和双峰, 能够反 映出物质来源复杂, 双峰峰值分布在 133 234 $\mu \mathrm{m}$ 和 294 1041 $\mu \mathrm{m} ; 8$ 个冰水沉积物样品中有 2 个样品 JQ-02、JQ-04 呈单峰, 其余样品均为多峰和双峰, 峰 值分布在 176 234 $\mu \mathrm{m}$ 和 493 653 $\mu \mathrm{m}$ 。

\subsection{2 粒度变化及其原因}

标准差对图解平均值散点图(图 4)对区分不同 类型沉积物的差异最有效(Landim et al, 1968), 从图 4 可以看出, 冰水沉积物相对于冰碛物粒径大而标

表 3 研究区冰川沉积物粒度分布及统计参数

Tab.3 Grain size and statistical parameters of the glacier deposits of the study area

\begin{tabular}{|c|c|c|c|c|c|c|c|}
\hline 样品编号 & $\begin{array}{l}<2.0 \mu \mathrm{m} \\
\text { 粘粒 } / \%\end{array}$ & $\begin{array}{l}2.0 \sim 63 \mu \mathrm{m} \\
\text { 粉砂级 } / \%\end{array}$ & $\begin{array}{l}>63 \mu \mathrm{m} \\
\text { 砂级 } / \%\end{array}$ & $\begin{array}{c}\text { 平均值 }\left(M_{z}\right) \\
/ \mu \mathrm{m}\end{array}$ & $\begin{array}{c}\text { 标准差 } \\
\left(\sigma_{i}\right)\end{array}$ & $\begin{array}{c}\text { 偏度 } \\
\left(S_{k}\right)\end{array}$ & $\begin{array}{l}\text { 峰态 } \\
\left(K_{g}\right)\end{array}$ \\
\hline RQ-01 & 0.60 & 8.99 & 90.41 & 493.12 & 2.00 & 0.44 & 0.93 \\
\hline RQ-02 & 1.46 & 23.92 & 74.62 & 137.74 & 2.10 & 0.08 & 1.18 \\
\hline RQ-03 & 3.28 & 29.32 & 67.40 & 111.11 & 2.55 & 0.34 & 0.86 \\
\hline RQ-04 & 3.73 & 28.9 & 67.37 & 107.32 & 2.56 & 0.51 & 0.82 \\
\hline RQ-05 & 1.29 & 15.84 & 82.87 & 213.16 & 2.00 & 0.32 & 1.25 \\
\hline RQ-06 & 1.65 & 28.75 & 69.60 & 111.11 & 2.19 & 0.15 & 1.03 \\
\hline BD-01 & 2.83 & 32.76 & 64.40 & 121.58 & 2.66 & 0.33 & 0.78 \\
\hline BD-02 & 3.78 & 36.82 & 59.40 & 86.57 & 2.66 & 0.18 & 0.92 \\
\hline BD-03 & 3.28 & 26.57 & 70.15 & 118.26 & 2.43 & 0.34 & 1.07 \\
\hline BD-04 & 2.98 & 31.53 & 65.49 & 125.87 & 2.66 & 0.27 & 0.81 \\
\hline BD-05 & 4.13 & 47.78 & 48.09 & 59.54 & 2.62 & 0.05 & 0.96 \\
\hline BD-07 & 2.58 & 52.98 & 44.44 & 55.94 & 2.53 & -0.13 & 0.85 \\
\hline 冰碛物平均值 & 2.63 & 30.35 & 67.02 & 145.11 & 2.41 & 0.24 & 0.96 \\
\hline RQ-07 & 0.50 & 9.38 & 90.11 & 257.03 & 1.46 & 0.19 & 1.08 \\
\hline JQ-01 & 0.52 & 2.94 & 96.54 & 226.88 & 0.94 & -0.05 & 0.94 \\
\hline JQ-02 & 2.43 & 51.26 & 46.31 & 51.12 & 1.30 & 0.29 & 1.16 \\
\hline JQ-03 & 1.49 & 18.32 & 80.19 & 188.16 & 2.02 & 0.31 & 1.10 \\
\hline JQ-04 & 0.25 & 3.24 & 96.50 & 360.98 & 1.11 & 0.27 & 0.96 \\
\hline JQ-05 & 0.40 & 6.95 & 92.65 & 299.37 & 1.40 & 0.14 & 0.93 \\
\hline BD-06 & 0.81 & 10.66 & 88.53 & 309.93 & 1.68 & 0.37 & 1.10 \\
\hline BD-08 & 1.66 & 38.92 & 59.42 & 100.83 & 2.47 & 0.13 & 0.81 \\
\hline 冰水沉积物平均值 & 1.01 & 17.71 & 81.28 & 224.29 & 1.55 & 0.21 & 1.01 \\
\hline 平均值 & 1.98 & 25.29 & 72.72 & 176.78 & 2.07 & 0.23 & 0.98 \\
\hline
\end{tabular}




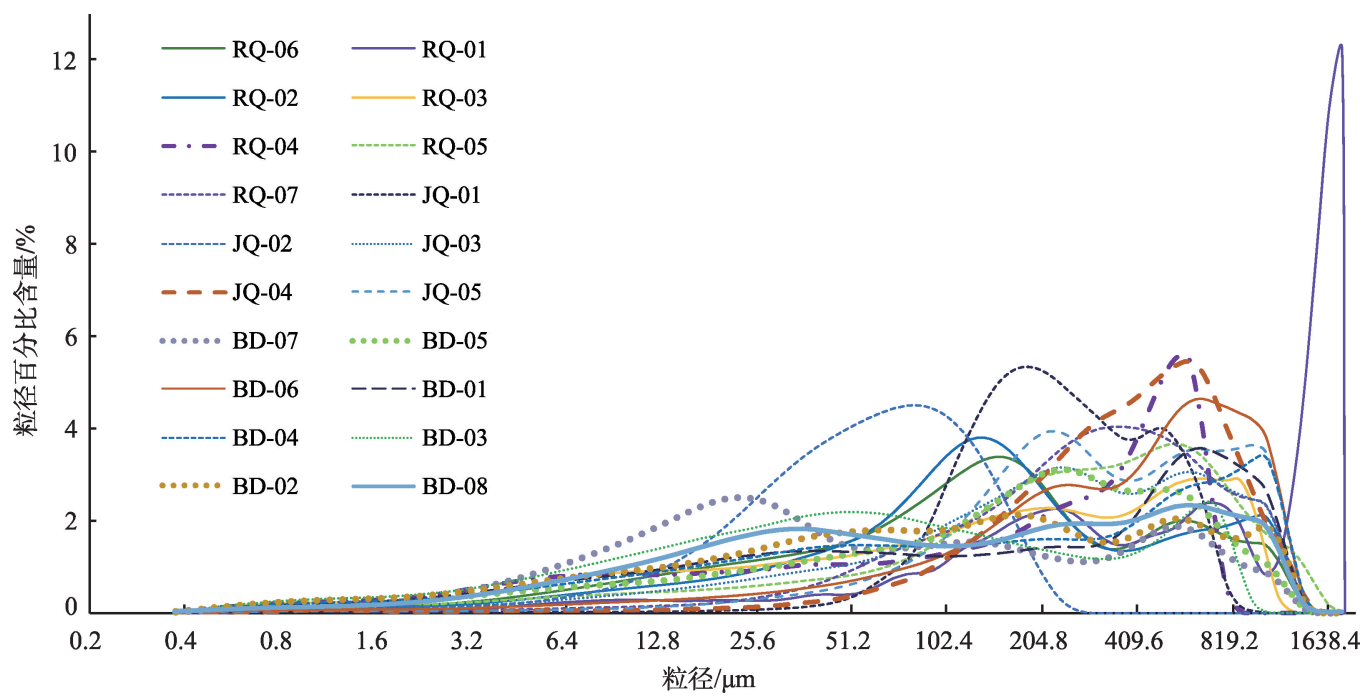

图 3 研究区冰川沉积物 $\leqslant 2 \mathrm{~mm}$ 粒径频率分布

Fig. $3 \leqslant 2 \mathrm{~mm}$ grain size frequency distribution of the glacier deposits of the study area

准差小, 说明冰水沉积物以砂级为主分选性较好。 因此, 为了避免不同性质沉积物对粒度产生的影 响, 只对比冰碛物粒度的空间变化, 从图 5 中看出研 究区冰碛物离冰川作用源头距离越远粒径越小, 一 方面是因为被冰川搬运越远，受到磨蚀、压碎越多， 导致粒径越小; 另一方面是因为距离冰斗近的冰碛

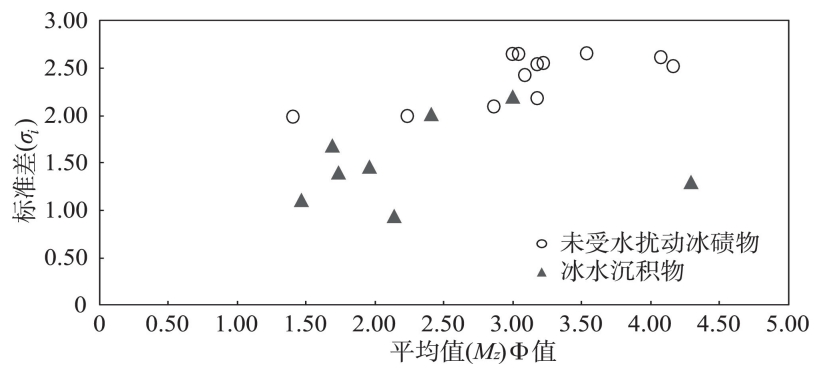

图 4 概括图解标准差对图解平均值散点图

Fig.4 Sediment standard deviation versus skew

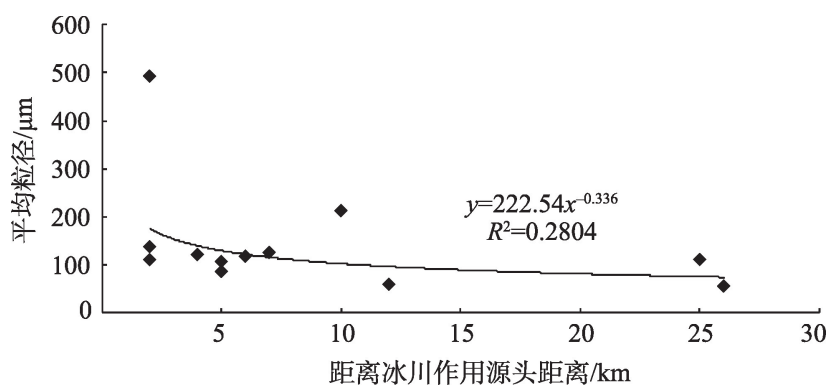

图 5 研究区内冰碛物平均粒径与距冰川作用 源头距离散点图

Fig.5 Relationship between average grain size of the tills in the study area and distance from the source of the glaciers
物沉积年龄相对较小,而距离冰斗远的冰碛物沉积 年龄相对较大, 冰碛物的粒径随着沉积年龄的增 大、风化时间的增长而减小。

\section{3 磁化率特征}

3.3.1 冰川沉积物磁化率

由表 4 可以看出, 该地区冰川沉积物的母岩以 花岗岩为主,岩性差别不大,但低频(质量)磁化率相 差较大 (介于 $8.72 \times 10^{-8} \sim 298.00 \times 10^{-8} \mathrm{~m}^{3} \cdot \mathrm{kg}^{-1}$ ), 该地区 冰川沉积物磁化率的平均值为 $83.30 \times 10^{-8} \mathrm{~m}^{3} \cdot \mathrm{kg}^{-1}$, 冰碛物质量磁化率的平均值 $\left(19.82 \times 10^{-8} \mathrm{~m}^{3} \cdot \mathrm{kg}^{-1}\right)$ 和 变幅 $\left(8.72 \times 10^{-8} \sim 42.95 \times 10^{-8} \mathrm{~m}^{3} \cdot \mathrm{kg}^{-1}\right)$ 都要小于冰水沉 积物 (平均值 $178.51 \times 10^{-8} \mathrm{~m}^{3} \cdot \mathrm{kg}^{-1}$, 变幅 $17.43 \times 10^{-8} \sim$ $\left.298.00 \times 10^{-8} \mathrm{~m}^{3} \cdot \mathrm{kg}^{-1}\right)$ 。

\subsection{2 磁化率变化及其原因}

沉积物的磁化率及频率磁化率与成壤强度有 关。对于研究区内冰碛物的低频磁化率值而言, 总 体较低 $\left(19.82 \times 10^{-8} \mathrm{~m}^{3} \cdot \mathrm{kg}^{-1}\right)$ 且不同期次差距不大, 总 体较低是受母岩影响, 该地区母岩以花岗岩、砂岩、 灰岩为主, 其磁化率值较小 (表 5), 不同期次差距不 大是由于冰川沉积物以物理风化为主, 成壤条件 弱, 不同期次沉积物磁化率差别不明显(刘亮, 2012)。对于研究区内不同类型冰川沉积物的质量 磁化率值而言, 冰碛物质量磁化率的平均值和变幅 均小于冰水沉积物, 磁铁矿集中分布的粒级与冰水 沉积物组成的粒级相似, 所以冰水沉积物的磁化率 的变幅比较大(Björck et al, 2010)。对于研究区内 冰川沉积物的频率磁化率值而言, 质量磁化率值总 体较低, 导致频率磁化率的误差较大, 对气候的指 
表 4 研究区冰川沉积物磁化率特征

Tab.4 Magnetic susceptibility of the glacier deposits

\section{of the study area}

\begin{tabular}{lccc}
\hline 样品编号 & $\begin{array}{c}\text { 低频磁化率 } \\
/\left(10^{-8} \mathrm{~m}^{3} \cdot \mathrm{kg}^{-1}\right)\end{array}$ & $\begin{array}{c}\text { 高频磁化率 } \\
/\left(10^{-8} \mathrm{~m}^{3} \cdot \mathrm{kg}^{-1}\right)\end{array}$ & $\begin{array}{c}\text { 频率磁 } \\
\text { 化率/\% }\end{array}$ \\
\hline RQ-01 & 8.72 & 8.62 & 1.15 \\
RQ-02 & 10.10 & 10.08 & 0.20 \\
RQ-03 & 13.38 & 12.79 & 4.41 \\
RQ-04 & 42.95 & 42.43 & 1.21 \\
RQ-05 & 13.61 & 14.39 & -5.73 \\
RQ-06 & 17.17 & 18.05 & -5.13 \\
BD-01 & 12.36 & 12.24 & 0.97 \\
BD-02 & 25.56 & 25.15 & 1.60 \\
BD-03 & 26.22 & 25.96 & 0.99 \\
BD-04 & 20.98 & 21.63 & -3.10 \\
BD-05 & 15.39 & 15.03 & 2.34 \\
BD-07 & 31.39 & 31.21 & 0.57 \\
冰碛物平均值 & 19.82 & 19.80 & -0.04 \\
\hline RQ-07 & 17.43 & 17.38 & 0.29 \\
JQ-01 & 210.92 & 203.89 & 3.33 \\
JQ-02 & 248.23 & 246.66 & 0.63 \\
JQ-03 & 298.00 & 288.01 & 3.35 \\
JQ-04 & 273.26 & 263.55 & 3.55 \\
JQ-05 & 93.38 & 90.94 & 2.61 \\
BD-06 & 62.65 & 62.57 & 0.13 \\
BD-08 & 224.23 & 220.13 & 1.83 \\
冰水沉积物平均值 & 178.51 & 174.14 & 1.97 \\
\hline 平均值 & 83.30 & 81.54 & 0.76 \\
\hline & & &
\end{tabular}

示作用较弱(胡守云等, 2001)。

将研究区与其他地区同一冰期冰川沉积物的 质量磁化率进行对比(张威等, 2012), 他念他翁山 (末次冰盛期: $21.28 \times 10^{-8} \mathrm{~m}^{3} \cdot \mathrm{kg}^{-1}$; 末次冰期: $15.39 \times$ $10^{-8} \mathrm{~m}^{3} \cdot \mathrm{kg}^{-1}$; 倒数第二次冰期: $31.39 \times 10^{-8} \mathrm{~m}^{3} \cdot \mathrm{kg}^{-1}$ )、 贺兰山(末次冰盛期: $36.45 \times 10^{-8} \mathrm{~m}^{3} \cdot \mathrm{kg}^{-1}$; 末次冰期 : $41.66 \times 10^{-8} \mathrm{~m}^{3} \cdot \mathrm{kg}^{-1}$ )、螺䯽山(末次冰期 : $21.11 \times 10^{-8}$ $\mathrm{m}^{3} \cdot \mathrm{kg}^{-1}$; 倒数第二次冰期: $18.21 \times 10^{-8} \mathrm{~m}^{3} \cdot \mathrm{kg}^{-1}$ )、白马 雪山(末次冰盛期: $8.27 \times 10^{-8} \mathrm{~m}^{3} \cdot \mathrm{kg}^{-1}$; 倒数第二次冰 期: $\left.8.81 \times 10^{-8} \mathrm{~m}^{3} \cdot \mathrm{kg}^{-1}\right)$, 发现不同地区同一冰期质量 磁化率相差较大, 同一地区不同冰期质量磁化率相 差较小。对于同一研究区而言, 磁化率的大小变化 不明显主要与冰川沉积物以物理风化为主、成壤条
件弱有关, 对于不同研究区而言, 磁化率相差较大 主要与不同地区母岩岩性相差较大有关。

\section{4 化学元素特征}

\subsection{1 化学元素分布特征}

表 6 为该地区冰川沉积物的主要化学元素,可 以看出他念他翁山冰川沉积物中 $\mathrm{SiO}_{2}$ 含量最多, 其 次是 $\mathrm{Al}_{2} \mathrm{O}_{3}$ 。他念他翁山地区的冰水沉积物相对于 冰碛物, $\mathrm{SiO}_{2} 、 \mathrm{CaO} 、 \mathrm{~K}_{2} \mathrm{O}$ 相对较多, 而 $\mathrm{Al}_{2} \mathrm{O}_{3} 、 \mathrm{MgO}$ 、 $\mathrm{Na}_{2} \mathrm{O} 、 \mathrm{TiO}_{2} 、 \mathrm{P}_{2} \mathrm{O}_{5} 、 \mathrm{MnO}$ 含量较少。 $\mathrm{SiO}_{2}$ 在冰水沉积 物中要多于冰碛物, 主要是由于冰水沉积物以砂为 主, 而砂的成分以石英和长石类矿物为主, 它们包 含的化学元素中 $\mathrm{SiO}_{2}$ 含量较多(杜德文等, 2003)。 他念他翁山中段冰川沉积物中 $\mathrm{SiO}_{2}$ 含量的平均值 为 $66.88 \%$, 比玛雅雪山(33.16\%)、扎尔那山 $(54.46 \%)$ 和马衔山(56.01\%)高(张威, 崔之久等, 2016), 这也 反映出了随着纬度的增高, 降水量和温度降低, 冰 川表层的 $\mathrm{SiO}_{2}$ 不易被带走(吴积善等, 1990), 因此向 冰川沉积物内部积累的较少。表 7 给出了他念他翁 山中段冰川沉积物主要元素的相关关系, 从表中可 以看出 $\mathrm{SiO}_{2} 、 \mathrm{CaO} 、 \mathrm{~K}_{2} \mathrm{O} 、 \mathrm{Na}_{2} \mathrm{O}$ 与大部分元素呈负相 关。 $\mathrm{SiO}_{2}$ 是他念他翁山地区冰川沉积物中最主要 的化学元素,它的多少对其他元素有显著的影响 (秦蕴珊, 1987; 王国庆等, 2007)。

\subsection{2 化学元素变化及其意义}

CIA 值对于研究沉积物的风化程度有重要作 用(Nesbitt et al,1984; 邵菁清等, 2012)。Nesbitt等 (1982)提出了 CIA 的计算公式:

$\mathrm{CIA}=\left[\mathrm{Al}_{2} \mathrm{O}_{3} /\left(\mathrm{Al}_{2} \mathrm{O}_{3}+\mathrm{CaO}^{*}+\mathrm{Na}_{2} \mathrm{O}+\mathrm{K}_{2} \mathrm{O}\right)\right] \times 100(1)$

公式中各氧化物的含量用摩尔数表示, 其中其 中 $\mathrm{CaO}^{*}$ 代表硅酸盐中的 $\mathrm{CaO}$, 对碳酸盐和磷灰石含 量进行校正,校正时使用 Mclennan(1993)提出的方 法, 如果 $\mathrm{CaO}$ 含量小于 $\mathrm{Na}_{2} \mathrm{O}$ 的含量, 则 $\mathrm{CaO}^{*}$ 采用 $\mathrm{CaO}$ 含量; 如果 $\mathrm{CaO}$ 含量大于 $\mathrm{Na}_{2} \mathrm{O}$ 含量, 则认为 $\mathrm{CaO}^{*}$ 含量相当于 $\mathrm{Na}_{2} \mathrm{O}$ 含量(袁方等, 2017)。研究区 冰川沉积物 CIA 值(59.67)很低, 表明了沉积物是在 寒冷干燥的气候条件下形成的(冯连君等, 2003), 具 有以物理风化为主、化学风化较弱的特点。研究区 冰碛物的 CIA 值(62.39)大于冰水沉积物(55.58), 说 明该地区冰碛物的风化程度大于冰水沉积物。

表 5 常见岩石类型的磁化率(Dearing, 1994)

Tab.5 Average magnetic susceptibility of common rockes (Dearing, 1994)

\begin{tabular}{cccccccccc}
\hline 岩石类型 & 花岗岩 & 白云质灰岩 & 玄武岩 & 片麻岩 & 片岩 & 板岩 & 泥岩 & 页岩 & 粉砂岩 \\
\hline 磁化率值 $/\left(10^{-8} \mathrm{~m}^{3} \cdot \mathrm{kg}^{-1}\right)$ & 2.6 & 1.9 & 855.6 & 14.4 & 9.0 & 13.6 & 10.8 & 3.0 & 4.5 \\
\hline
\end{tabular}


表 6 他念他翁山中段地区冰川沉积物主要元素组成

Tab.6 Major elements of the glacier deposits in the middle Tenasserim Chain

\begin{tabular}{|c|c|c|c|c|c|c|c|c|c|c|c|}
\hline 样品编号 & $\mathrm{SiO}_{2}$ & $\mathrm{Al}_{2} \mathrm{O}_{3}$ & $\mathrm{Fe}_{2} \mathrm{O}_{3}$ & $\mathrm{CaO}$ & $\mathrm{K} 2 \mathrm{O}$ & $\mathrm{MgO}$ & $\mathrm{Na}_{2} \mathrm{O}$ & $\mathrm{TiO}_{2}$ & $\mathrm{P}_{2} \mathrm{O}_{5}$ & $\mathrm{MnO}$ & CIA \\
\hline RQ-01 & 64.72 & 15.01 & 2.50 & 1.27 & 5.69 & 0.75 & 1.85 & 0.35 & 0.16 & 0.07 & 56.59 \\
\hline RQ-02 & 66.30 & 13.99 & 3.53 & 1.19 & 5.28 & 0.81 & 1.67 & 0.41 & 0.25 & 0.05 & 56.83 \\
\hline RQ-03 & 66.52 & 14.46 & 1.89 & 1.20 & 5.76 & 0.71 & 1.76 & 0.37 & 0.25 & 0.02 & 56.10 \\
\hline RQ-04 & 63.24 & 14.42 & 3.50 & 0.66 & 4.26 & 0.63 & 1.05 & 0.47 & 0.49 & 0.07 & 65.67 \\
\hline RQ-05 & 65.42 & 14.92 & 3.70 & 0.50 & 3.96 & 0.76 & 0.75 & 0.51 & 0.17 & 0.04 & 69.88 \\
\hline RQ-06 & 69.33 & 12.64 & 3.34 & 1.01 & 3.45 & 0.90 & 1.24 & 0.45 & 0.18 & 0.06 & 62.41 \\
\hline BD-01 & 66.43 & 16.09 & 3.52 & 0.46 & 3.41 & 0.82 & 2.21 & 0.48 & 0.10 & 0.08 & 66.34 \\
\hline BD-02 & 67.20 & 14.11 & 2.90 & 0.51 & 2.27 & 0.82 & 3.16 & 0.41 & 0.10 & 0.05 & 62.17 \\
\hline BD-03 & 68.15 & 14.38 & 3.06 & 0.59 & 2.38 & 0.97 & 3.21 & 0.41 & 0.06 & 0.06 & 61.68 \\
\hline BD-04 & 71.21 & 12.83 & 1.82 & 0.45 & 1.97 & 0.58 & 3.64 & 0.29 & 0.06 & 0.04 & 58.93 \\
\hline BD-05 & 61.97 & 14.74 & 5.49 & 2.24 & 2.43 & 1.03 & 1.55 & 0.54 & 0.11 & 0.10 & 65.59 \\
\hline BD-07 & 61.18 & 16.79 & 5.20 & 1.03 & 4.02 & 1.20 & 1.36 & 0.56 & 0.17 & 0.10 & 66.49 \\
\hline 冰碛物平均值 & 65.97 & 14.53 & 3.37 & 0.93 & 3.74 & 0.83 & 1.95 & 0.44 & 0.18 & 0.06 & 62.39 \\
\hline RQ-07 & 65.11 & 11.60 & 2.73 & 4.33 & 3.73 & 1.68 & 1.35 & 0.30 & 0.12 & 0.04 & 57.76 \\
\hline JQ-01 & 70.65 & 13.29 & 1.54 & 1.58 & 5.08 & 0.25 & 1.98 & 0.23 & 0.13 & 0.02 & 53.33 \\
\hline JQ-02 & 65.90 & 14.50 & 2.76 & 1.83 & 4.66 & 0.72 & 2.02 & 0.47 & 0.28 & 0.06 & 55.35 \\
\hline JQ-03 & 68.10 & 14.02 & 1.99 & 1.65 & 5.96 & 0.42 & 1.78 & 0.33 & 0.21 & 0.03 & 53.24 \\
\hline JQ-04 & 70.17 & 13.92 & 1.03 & 1.29 & 5.31 & 0.22 & 1.95 & 0.19 & 0.11 & 0.02 & 55.19 \\
\hline JQ-05 & 70.69 & 13.39 & 1.73 & 1.33 & 5.51 & 0.25 & 1.79 & 0.22 & 0.13 & 0.02 & 54.17 \\
\hline BD-06 & 71.44 & 12.54 & 1.97 & 1.06 & 4.34 & 0.67 & 2.35 & 0.26 & 0.08 & 0.06 & 54.44 \\
\hline BD-08 & 63.79 & 14.75 & 5.56 & 1.88 & 2.48 & 1.75 & 2.03 & 0.57 & 0.11 & 0.10 & 61.16 \\
\hline 冰水沉积物平均值 & 68.23 & 13.50 & 2.41 & 1.87 & 4.63 & 0.75 & 1.91 & 0.32 & 0.15 & 0.04 & 55.58 \\
\hline 平均值 & 66.88 & 14.12 & 2.99 & 1.30 & 4.10 & 0.80 & 1.94 & 0.39 & 0.16 & 0.05 & 59.67 \\
\hline
\end{tabular}

表 7 研究区冰川沉积物主要元素相关性矩阵

Tab.7 Correlation matrix of major elements of the glacier deposits of the study area

\begin{tabular}{|c|c|c|c|c|c|c|c|c|c|c|}
\hline & $\mathrm{SiO}_{2}$ & $\mathrm{Al}_{2} \mathrm{O}_{3}$ & $\mathrm{Fe}_{2} \mathrm{O}_{3}$ & $\mathrm{CaO}$ & $\mathrm{K}_{2} \mathrm{O}$ & $\mathrm{MgO}$ & $\mathrm{Na}_{2} \mathrm{O}$ & $\mathrm{TiO}_{2}$ & $\mathrm{P}_{2} \mathrm{O}_{5}$ & $\mathrm{MnO}$ \\
\hline $\mathrm{SiO}_{2}$ & 1 & & & & & & & & & \\
\hline $\mathrm{Al}_{2} \mathrm{O}_{3}$ & $-0.627^{* *}$ & 1 & & & & & & & & \\
\hline $\mathrm{Fe}_{2} \mathrm{O} 3$ & $-0.808^{* *}$ & $0.535^{*}$ & 1 & & & & & & & \\
\hline $\mathrm{CaO}$ & -0.222 & -0.416 & 0.060 & 1 & & & & & & \\
\hline $\mathrm{K}_{2} \mathrm{O}$ & 0.159 & -0.008 & $-0.510^{*}$ & 0.120 & 1 & & & & & \\
\hline $\mathrm{MgO}$ & $-0.618^{* *}$ & 0.091 & $0.718^{* * *}$ & $0.463^{*}$ & $-0.523^{*}$ & 1 & & & & \\
\hline $\mathrm{Na}_{2} \mathrm{O}$ & $0.475^{*}$ & -0.144 & -0.300 & -0.314 & $-0.449^{*}$ & -0.122 & 1 & & & \\
\hline $\mathrm{TiO}_{2}$ & $-0.799^{* *}$ & $0.647^{* *}$ & $0.912^{* *}$ & -0.137 & $-0.451^{*}$ & $0.604^{* *}$ & -0.284 & 1 & & \\
\hline $\mathrm{P}_{2} \mathrm{O}_{5}$ & -0.382 & 0.165 & 0.075 & -0.063 & 0.411 & -0.137 & $-0.544^{*}$ & 0.256 & 1 & \\
\hline $\mathrm{MnO}$ & $-0.703^{* *}$ & $0.541^{*}$ & $0.875^{* *}$ & -0.027 & $-0.514^{*}$ & $0.636^{* *}$ & -0.087 & $0.797^{* *}$ & 0.011 & 1 \\
\hline
\end{tabular}

注:***分别表示在 $0.05 、 0.01$ 水平(双侧)上显著相关。

在 A-CN-K 图中(图 6a)可以看出, 他念他翁山 中段冰川沉积物大致分布在上陆壳(UCC) 和陆源页 岩(PASS)连线上, 处于脱 $\mathrm{Ca} 、 \mathrm{Na}$ 的化学风化的早期 阶段, 与青藏高原东缘古冰川沉积物、洛川黄土、周 家沟黄土处于同一水平, 但部分样品向右偏离风化
趋势线, 说明沉积后受到了一定风化作用的影响。 在 A-CNK-FM 三角图中(图 6b), 研究区内的冰水沉 积物分布在斜长石与黑云母的连线附近, 远离 $\mathrm{Al}_{2} \mathrm{O}_{3}$ 顶点, 说明风化程度较低, 而冰碛物较冰水沉 积物离 $\mathrm{Al}_{2} \mathrm{O}_{3}$ 顶点更近, 说明其风化程度高于冰水 

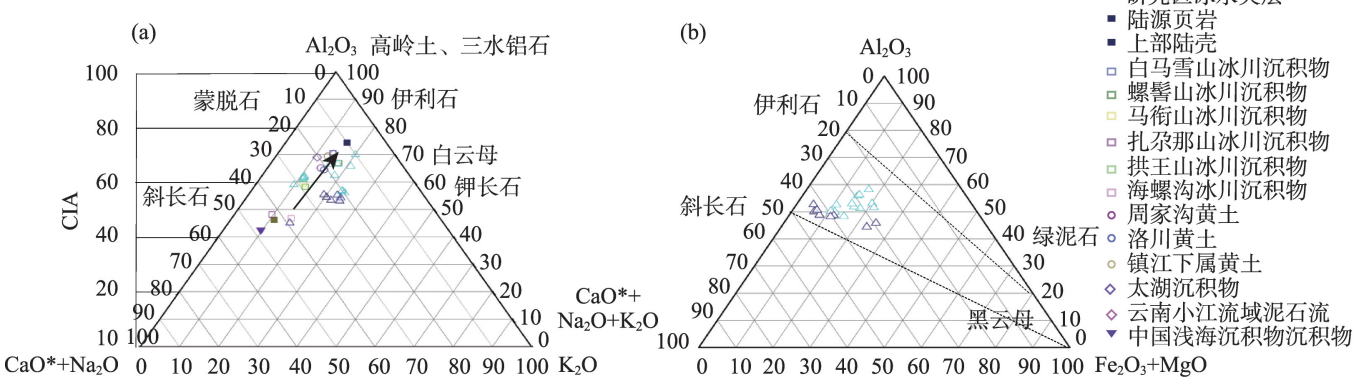

图 6 他念他翁山中段冰川沉积物的 A-CN-K(a)与 A-CNK-FM(b)三角图

Fig.6 A-CN-K and A-CNK-FM diagrams with the tills of the glacier deposits in the middle Tenasserim Chain

沉积物, 这与这与 CIA 指示的两者风化程度相 一致。

\subsection{3 化学元素对古气候演变的响应}

青古隆地区冰川沉积物的母岩岩性差别不大， 以花岗岩为主, 岩性对沉积物风化作用的影响较 小, 其主要影响因素为气候条件和风化时间, 因此 可以选取地球化学指标来推断不同阶段古气候的 特征。为了避免不同性质沉积物对化学元素分析 产生的影响, 只对比该地区冰碛物地球化学元素指 标与古气候演变之间的关系。

表 8 显示: 青古隆地区冰碛物 CIA 值较低,平均 值 63.52, 范围 58.92 66.48, 说明风化程度较低, 沉 积环境寒冷干燥。硅铝系数 sa 和硅铝铁系数 saf能 反映沉积物的风化和发育程度, 数值越大表明沉积 环境越干旱, 当 saf值 $>4$, 表示其具有冰碛物的特 征(冯连君等, 2003), 青古隆地区冰碛物样品 $\mathrm{sa}$ 和 saf的变化具有同步性且数值较大, 表明沉积环境较 干旱, 以物理风化为主, 化学风化微弱。碱金属淋 溶系数 $T$ 能够表示气候环境, 值越小表明环境越温 暖湿润。

MIS2 阶段(BD-01、BD-02、BD-03、BD-04)CIA

表 8 青古隆地区冰碛物地球化学指标

Tab.8 Geochemical parameters of the tills of the Qinggulong area

\begin{tabular}{ccccc}
\hline 采样编号 & CIA & sa & saf & $T$ \\
\hline BD-01 & 66.34 & 7.01 & 6.15 & 0.46 \\
BD-02 & 62.17 & 8.09 & 7.15 & 0.54 \\
BD-04 & 58.93 & 9.42 & 8.64 & 0.63 \\
BD-03 & 61.68 & 8.05 & 7.08 & 0.55 \\
BD-05 & 65.59 & 7.14 & 5.77 & 0.35 \\
BD-07 & 66.49 & 6.19 & 5.16 & 0.39 \\
\hline
\end{tabular}

注 : $\mathrm{sa}=\mathrm{SiO}_{2} / \mathrm{Al}_{2} \mathrm{O}_{3} ; \mathrm{saf}=\mathrm{SiO}_{2} /\left(\mathrm{Al}_{2} \mathrm{O}_{3}+\mathrm{Fe}_{2} \mathrm{O}_{3}\right) ; T=\left(\mathrm{Na}_{2} \mathrm{O}+\mathrm{K}_{2} \mathrm{O}\right) /$ $\mathrm{Al}_{2} \mathrm{O}_{3}$; 式中各参数为分子摩尔比。
值(平均值 62.28)为青古隆地区的最小值, 说明这一 阶段的风化作用较弱, 风化时间较短。硅铝系数 sa (平均值 8.14) 和硅铝铁系数 $\operatorname{saf}$ (平均值 7.26)也具有 同步性, 均为最大值, 说明该阶段降水最少, 气候最 干旱。碱金属淋溶系数 $T$ (平均值 0.54 ) 为青古隆地 区最大值, 值越大代表气候越干旱, 水热组合条件 越不好, 说明该阶段降水较少, 碱金属淋湿程度 低。通过以上指标可以看出, MIS2 阶段经历风化 程度最低、时间最短,该阶段的气候较为干旱,水热 组合条件不好,这与唐领余等(1999)通过钻孔孢粉 记录发现他念他翁山中段地区的仁措湖在 $18 \mathrm{kaBP}$ 左右气候寒冷干旱, 植被以藜、蒿为主的研究结果相 一致。

MIS3b 阶段(BD-05)CIA 值(65.59)为青古隆地 区的中间值,说明这一阶段的风化程度和风化时间 大于 MIS2 阶段而小于 MIS6 阶段。硅铝系数 sa 和 硅铝铁系数 saf相对于 MIS2 阶段均降低(为 7.13 和 5.76), 说明该阶段降水有所增加。碱金属淋溶系数 $T$ 最小 $(0.35)$, 水热组合条件相对较好, 说明此阶段 降水和气温都不是最低的。通过以上指标可以看 出, MIS3b 阶段经历风化程度和风化时间中等, 该 阶段的气候较为湿润, 降水量较 MIS2 阶段增加。 青古隆地区第三套冰碛物化学综合指标判断古气 候的结果与施雅风等(2002)通过研究全球 12 个地 区和 23 个地点发现 MIS3b 阶段冰进规模大于 MIS2 阶段,得出 MIS3b 冷期的降水比 MIS2 阶段丰富的 结果一致。

MIS6 阶段(BD-07), 该阶段 CIA 值(66.49)为青 古隆地区的最大值, 说明这一阶段的风化程度最大 和风化时间最长。硅铝系数 sa 和硅铝铁系数 saf均 为最小 (分别为 6.19 和 5.16), 说明该阶段降水相对 于 MIS2 和 MIS3b 阶段最多。碱金属淋溶系数 $T$ (0.39)大于 MIS3b 阶段而小于 MIS2 阶段,说明水热 
组合条件居中, 和硅铝系数 sa、硅铝铁系数对比可 以推断此阶段降水最多但气温较低。通过以上指 标可以看出, MIS6 阶段经历风化程度较高和时间 最长, 该阶段的降水量相对于 MIS2 阶段和 MIS3 阶 段较多,但气温较低,这与潘保田等(1997)研究青藏 高原东北部的冰楔假型发现倒数第二次冰期气温 为 $-10 \sim-11^{\circ} \mathrm{C}$, 低于现代当地气温约 $10^{\circ} \mathrm{C}$ 的严寒情 况相一致。

\section{5 矿物特征与环境}

\subsection{1 全岩矿物特征}

从表 9 可以看出, 冰川沉积物全样矿物的组成 以长石 $(55.30 \%)$ 、石英 $(32.55 \%)$ 为主, 其次分别是伊 利石 $(8.45 \%)$ 和绿泥石 $(3.20 \%)$ 。冰碛物主要的矿物 成分是长石和石英, 属于逆磁性矿物, 缺少铁美含 量较多的暗色矿物例如橄榄石、角闪石、辉石等, 所 以磁化率值较低(王建等, 1996; 张威等, 2012); 而冰 水沉积物中的绿泥石含量 $(2.63 \%)$ 相对于冰碛物的 绿泥石含量 $(3.85 \%)$ 较低, 冰水沉积物较高的磁化率 值与绿泥石在风化过程中释放大量铁、镁离子有关
(Proust et al, 1986)。对于青古隆地区, MIS2 阶段, 全岩矿物中粘土矿物(伊利石、绿泥石)含量最低(平 均值 $15.25 \%$ ), 这是因为风化时间最短所致; MIS3b 阶段, 粘土矿物含量最高(平均值 $17.00 \%$ ), 与此阶 段化学指标得出的水热组合条件相对较好结论相 一致; MIS6 阶段,粘土矿物含量为 $16.00 \%$, 与此阶 段化学指标得出的水热组合条件居中相一致。

\subsection{2 粘土矿物特征}

RQ-01、JQ-01、JQ-02、JQ-04、BD-06 在实验过 程中因为粘土含量过少而无法进行粘土矿物分析, 其余的样品经 X射线衍射仪测试分析(表 10): 冰川 沉积物中的粘土矿物以伊利石 (平均值 $77.53 \%$ ) 和 绿泥石(平均值 $20.47 \%$ ) 为主。研究区的岩性条件 主要以岩浆岩为主, 三叠系和侏罗系的沉积岩仅零 星分布, 且在采样的几条谷中几乎无出露, 因此沉 积岩的岩性对粘土矿物的分析结果几乎无影响。 沉积物中的粘土矿物会出现伊利石 $\rightarrow$ 绿泥石 $\rightarrow$ 蛭 石 $\rightarrow$ 蒙脱石 $\rightarrow$ 高岭石的总体演化趋势(Sheldon et al, 2009; Nordt et al, 2010; 方谦等, 2018), 伊利石和

表 9 他念他翁山中段地区冰川沉积物全岩矿物分析结果

Tab.9 Result of mineral liberation analysis of the glacier deposits in the middle Tenasserim Chain

\begin{tabular}{|c|c|c|c|c|c|c|}
\hline 样品编号 & 方解石 & 长石 & 石英 & 伊利石 & 绿泥石 & 闪石 \\
\hline RQ-01 & 1.00 & 66.00 & 27.00 & 2.00 & 3.00 & 1.00 \\
\hline RQ-02 & 1.00 & 64.00 & 28.00 & 4.00 & 3.00 & 0 \\
\hline RQ-03 & 1.00 & 72.00 & 24.00 & 1.00 & 2.00 & 0 \\
\hline RQ-04 & 0 & 47.00 & 39.00 & 9.00 & 5.00 & 0 \\
\hline RQ-05 & 0 & 44.00 & 41.00 & 10.00 & 5.00 & 0 \\
\hline RQ-06 & 0 & 39.00 & 49.00 & 10.00 & 2.00 & 0 \\
\hline BD-01 & 0 & 44.00 & 28.00 & 22.00 & 6.00 & 0 \\
\hline BD-02 & 0 & 43.00 & 45.00 & 8.00 & 4.00 & 0 \\
\hline BD-03 & 0 & 61.00 & 26.00 & 10.00 & 3.00 & 0 \\
\hline BD-04 & 0 & 52.00 & 40.00 & 6.00 & 2.00 & 0 \\
\hline BD-05 & 4.00 & 44.00 & 35.00 & 11.00 & 6.00 & 0 \\
\hline BD-07 & 0 & 55.00 & 29.00 & 14.00 & 2.00 & 0 \\
\hline 冰碛物平均值 & 0.58 & 52.58 & 34.25 & 8.92 & 3.58 & 0.08 \\
\hline RQ-07 & 0 & 49.00 & 41.00 & 7.00 & 3.00 & 0 \\
\hline JQ-01 & 0 & 70.00 & 25.00 & 3.00 & 1.00 & 1.00 \\
\hline JQ-02 & 0 & 70.00 & 24.00 & 4.00 & 2.00 & 0 \\
\hline JQ-03 & 0 & 62.00 & 32.00 & 4.00 & 2.00 & 0 \\
\hline JQ-04 & 0 & 64.00 & 34.00 & 2.00 & 0 & 0 \\
\hline JQ-05 & 0 & 66.00 & 30.00 & 3.00 & 1.00 & 0 \\
\hline BD-06 & 0 & 67.00 & 23.00 & 7.00 & 2.00 & 1.00 \\
\hline BD-08 & 0 & 27.00 & 31.00 & 32.00 & 10.00 & 0 \\
\hline 冰水沉积物平均值 & 0 & 59.38 & 30.00 & 7.75 & 2.63 & 0.25 \\
\hline 平均值 & 0.35 & 55.30 & 32.55 & 8.45 & 3.20 & 0.15 \\
\hline
\end{tabular}


表 10 他念他翁山中段地区冰川沉积物粘土矿物分析结果

Tab.10 Result of clay minerals analysis of the glacier deposits in the middle Tenasserim Chain

\begin{tabular}{cccc}
\hline 样品编号 & 伊利石 & 高岭石 & 绿泥石 \\
\hline RQ-02 & 57.00 & - & 43.00 \\
RQ-03 & 48.00 & - & 52.00 \\
RQ-04 & 76.00 & - & 24.00 \\
RQ-05 & 65.00 & - & 35.00 \\
RQ-06 & 96.00 & - & 4.00 \\
BD-01 & 94.00 & 6.00 & - \\
BD-02 & 74.00 & - & 26.00 \\
BD-03 & 74.00 & - & 26.00 \\
BD-04 & 75.00 & - & 25.00 \\
BD-05 & 93.00 & 7.00 & - \\
BD-07 & 96.00 & 4.00 & - \\
RQ-07 & 84.00 & - & 16.00 \\
JQ-03 & 55.00 & - & 45.00 \\
JQ-05 & 89.00 & - & 11.00 \\
BD-08 & 87.00 & 13.00 & - \\
平均值 & 77.53 & 2.00 & 20.47 \\
\hline
\end{tabular}

绿泥石这 2 种矿物是沉积物风化的最初阶段, 说明 沉积物经历的风化过程以物理风化为主, 沉积物经 历了寒冷干燥的气候环境(Liu et al, 2010; Wang et al, 2013)。从时间上来看, 对于青古隆地区, MIS2 阶段, 粘土矿物中高岭石含量最低(平均值 $1.50 \%$ ), 是由于风化时间最短所致; MIS3b 阶段, 高岭石含 量最高(平均值 $7.00 \%$ ), 是由于水热组合条件相对 较好所致; MIS6 阶段, 高岭石含量为 $4.00 \%$, 是因为 该阶段水热组合条件一般。从空间上来看,在所有 冰川沉积物粘土矿物样品中, 只有 4 号槽和 5 号槽 冰川沉积物样品含有高岭石, 这是由于这 2 条谷相 对于其他槽谷, 坡度较陡、排水顺畅, 利于高岭石的 形成(Dixon et al, 1989; Varga et al, 2011; 方谦等, 2018)。

\section{4 结论}

依据光释光测年、粒度、磁化率、化学元素以及 矿物分析结果, 主要结论如下:

(1) 研究区冰碛物的粒径在空间分布上具有明 显的特征, 冰碛物离冰川源头越远粒径越小,一方 面是因为冰碛物被冰川搬运越远, 受到磨蚀、压碎 越多, 所以粒径越小; 另一方面是因为随着沉积年 龄的增大、风化时间的增长而导致粒径减小。

(2) 通过不同时空冰川沉积物磁化率对比得
出:对于同一研究区而言, 磁化率的大小变化不明 显, 主要与冰川沉积物以物理风化为主, 成壤条件 弱有关, 对于不同研究区而言, 磁化率相差较大, 主 要与不同地区母岩岩性相差较大有关。

(3) 研究区冰川沉积物的全岩矿物组成以石 英、长石为主, 伊利石、绿泥石次之; 粘土矿物以伊 利石和绿泥石为主, 说明处于沉积物风化的最初阶 段,沉积物经历的风化过程以物理风化为主, 形成 的气候环境寒冷干燥。

(4) 地球化学和矿物学指标反映出青古隆地区 古气候的总体特征是寒冷干燥,但在不同阶段古气 候具有不同的特点。在末次冰盛期时气候最为干 旱, 末次冰期中冰阶时气候较为干旱、降水量相对于 末次冰盛期有所增加,倒数第二次冰期降水量相对 于末次冰盛期和末次冰期中冰阶较多,但气温较低。

\section{参考文献(References)}

陈安东, 顾佳妮, 赵志中, 等. 2016. 云南大理点苍山末次冰 期冰碛物石英砂扫描电镜形态特征分析 [J]. 冰川冻土, 38(2): 453-462. [Chen A D, Gu J N, Zhao Z Z, et al. 2016. Quartz grains SEM surface microtextures of Quaternary glacial sediments along the Diancang Mountain in Yunnan, Southwest China. Journal of Glaciology and Geocryology, 38(2): 453-462. ]

陈福忠, 廖国兴. 1983. 昌都地区地质基本特征 [M] / 青藏高 原地质文集. 北京: 地质出版社. [Chen F Z, Liao G X. 1983. The basic geological characteristics in Qamdo district//Contribution to the Geology of the Qinghai-Xizang (Tibet) Plateau. Beijing, China: Geological Publishing House. ]

陈仁容, 周尚哲, 邓应涁. 2012. 末次冰期冰碛垄系列的形态 特征及其形成探讨: 以帕隆藏布江谷地为例 [J]. 冰川冻 土, 34(4): 836- 847. [Chen R R, Zhou S Z, Deng Y B. 2012. Morphological characteristics of glacial deposits during the Last Glaciation: Taking the Parlung Zangbo River basins as an example. Journal of Glaciology and Geocryology, 34(4): 836-847. ]

崔之久, 杨健夫. 1999. 中国台湾高山第四纪冰川之确证 [J]. 科学通报, 44(20): 2220-2224. [Cui Z J, Yang J F. 1999. Confirmation of the Quaternary Glacier in Taiwan, China. Chinese Science Bulletin, 44(20): 2220-2224. ]

崔之久, 易朝路. 1994. 天山和阿尔泰山冰碛物显微结构特 征 [J]. 应用基础与工程科学学报, 2(4): 313-319. [Cui Z J, Yi C L. 1994. Microfabric study of till at Mountains Tianshan and Altay. Journal of Basic Science and Engineering, 2(4): 313-319. ] 
杜德文, 石学法, 孟宪伟, 等. 2003. 黄海沉积物地球化学的 粒度效应 [J]. 海洋科学进展, 21(1): 78-82. [Du D W, Shi X F, Meng X W, et al. 2003. Geochemical granularity effect of sediment in the Yellow Sea. Advances in Marine Science, 21(1): 78-82. ]

方谦, 洪汉烈, 赵璐璐, 等. 2018. 风化成土过程中自生矿物 的气候指示意义 [J]. 地球科学, 43(3): 753-769. [Fang Q, Hong H L, Zhao L L, et al. 2018. Climatic implication of authigenic minerals formed during pedogenic weathering processes. Earth Science, 43(3): 753-769. ]

冯连君, 储雪蕾, 张启锐, 等. 2003. 化学蚀变指数(CIA)及其 在新元古代碎屑岩中的应用 [J]. 地学前缘, 10(4): 539544. [Feng L J, Chu X L, Zhang Q R, et al. 2003. CIA (chemical index of alteration) and its applications in the Neoproterozoic clastic rocks. Earth Science Frontiers, 10 (4): 539-544. ]

高由禧, 蒋世逵, 张谊光, 等. 1984. 西藏气候 [M]. 北京: 科学 出版社. [Gao Y X, Jiang S K, Zhang Y G, et al. 1984. Tibet climate. Beijing, China: Science Press. ]

胡恩, 易朝路, 李艳军. 2010. 珠穆朗玛峰线布河谷冰碛地貌 测量与演化研究 [J]. 冰川冻土, 32(2): 316-324. [Hu E, Yi C L, Li Y J. 2010. Observation and evolution investigation of the moraine geomorphology in the Rongbuk Valley of Mount Qomolangma. Journal of Glaciology and Geocryology, 32(2): 316-324. ]

胡守云, 邓成龙, Appel E, 等. 2001. 湖泊沉积物磁学性质的 环境意义 [J]. 科学通报, 46(17): 1491-1494. [Hu S Y, Deng C L, Appel E, et al. 2001. Environmental significance of magnetic properties of lake sediments. Chinese Science Bulletin, 46(17): 1491-1494. ]

康建成. 1989. 贡巴冰川边缘冰碛垄特征与形成过程 $[\mathrm{J}]$. 冰 川冻土, 11(2): 172-176. [Kang J C. 1989. Grain-size characteristics of glacial debris, and explanation of the processes of glacial transports and sediments at the Gongba Glaciers in Mt. Gongga. Journal of Glaciology and Geocryology, 11(2): 172-176. ]

李全莲, 张成龙, 武小波, 等. 2015. 中国西部冰川冰尘的粒 度及矿物组成 [J]. 山地学报, 33(2): 166-172. [Li Q L, Zhang C L, Wu X B, et al. 2015. Grain size distribution and mineral components of cryoconites of glaciers in Western China. Mountain Research, 33(2): 166-172. ]

李亚兵, 易朝路, 魏灵, 等. 2006. 慕士塔格新冰期以来冰碛 物风化成土特征 [J]. 冰川冻土, 28(3): 355-359. [Li Y B, Yi C L, Wei L, et al. 2006. Grain-size features and magnetic susceptibility characteristic of the surfacelayer of the Moraines in the Muztag Ata. Journal of Glaciology and Geocryology, 28(3): 355-359. ]

刘耕年, 张跃, 傅海荣, 等. 2009. 贡嘎山海螺沟冰川沉积特 征与冰下过程研究 [J]. 冰川冻土, 31(1): 68-74. [Liu G
N, Zhang Y, Fu H R, et al. 2009. Sedimentary characteristics and subglacial processes of the glacial deposits in Hailuogou Glacier, Gongga Mountain. Journal of Glaciology and Geocryology, 31(1): 68-74. ]

刘亮. 2012. 云南千湖山第四纪冰川作用与环境演变 [D]. 大 连: 辽宁师范大学. [Liu L. 2012. Quaternary glaciations and the environmental evolution in Qianhu Mountain of Yunnan Province. Dalian, China: Liaoning Normal University. ]

刘亮. 2017. 阿尔泰山喀纳斯河谷第四纪冰川地貌演化与年 代学研究 [D]. 大连: 辽宁师范大学. [Liu L. 2017. Quaternary glacial landforms evolution and geochronology in the Kanas River valley, Altai Mountains, China. Dalian, China: Liaoning Normal University. ]

刘雯雯, 徐鹏, 朱海峰, 等. 2015. 藏东南地区树轮冰川学研 究进展 [J]. 第四纪研究, 35(5): 1238-1244. [Liu WW, Xu P, Zhu H F, et al. 2015. A review on dendroglaciology study in southeast Tibetean Plateau. Quaternary Sciences, 35(5): 1238-1244. ]

潘保田, 陈发虎. 1997. 青藏高原东北部 15 万年来的多年冻 土演化 [J]. 冰川冻土, 19(2): 124-132. [Pan B T, Chen F H. 1997. Permafrost evolution in the northeastern Qinghai-Tibetan Plateau during the last 150000 years. Journal of Glaciology and Geocryology, 19(2): 124-132. ]

秦蕴珊. 1987. 东海地质 [M]. 北京: 科学出版社. [Qin Y S. 1987. East China Sea geology. Beijing, China: Science Press. ] 邵菁清, 杨守业. 2012. 化学蚀变指数(CIA)反映长江流域的 硅酸盐岩化学风化与季风气候? [J]. 科学通报, 57(11): 933-942. [Shao J Q, Yang S Y. 2012. Does chemical index of alteration (CIA) reflect silicate weathering and monsoonal climate in the Changjiang River basin? Chinese Science Bulletin, 57(11): 933-942. ]

施雅风, 姚檀栋. 2002. 中低纬度 MIS 3b (54 44ka BP) 冷期 与冰川前进 [J]. 冰川冻土, 24(1): 1-9. [Shi Y F, Yao S D. 2002. MIS 3b (54-44 ka BP) cold period and glacial advance in middle and low latitudes. Journal of Glaciology and Geocryology, 24(1): 1-9. ]

苏珍, 蒲健辰. 1966. 横断山冰川发育条件、数量及形态特征 $[\mathrm{M}] / /$ 李吉均. 横断山冰川. 北京: 科学出版社. [ $\mathrm{Su} \mathrm{Z,Pu}$ J C. 1966. Development conditions, number and morphological characteristics of glaciers in the Hegnduan Mountains region // Li J J. Glaciers in the Hengduan Mountains. Beijing, China: Science Press. ]

唐领余, 沈才明, Kam B L, 等. 1999. 南亚古季风的演变: 西 藏新的高分辨率古气候记录 [J]. 科学通报, 44(18): 20042007. [Tang L Y, Shen C M, Kam B L, et al. 1999. Evolution of the ancient monsoon in South Asia: Tibet's new high-resolution paleoclimatic record. Chinese Science Bulletin, 44(18): 2004-2007. ]

唐领余, 王睿, 孔昭宸. 1983. 西藏东南部若果冰川的孢粉分 
析 [J]. 植物学报, 25(2): 75-82, 111. [Tang L Y, Wang R, Kong Z C. 1983. Pollen analytical investigation of the Ruoguo glacier in southeast Xizang. Journal of Integrative Plant Biology, 25(2): 75-82, 111. ]

王国庆, 石学法, 刘炎光, 等. 2007. 长江口南支沉积物元素 地球化学分区与环境指示意义 [J]. 海洋科学进展, 25 (4): 408-418. [Wang G Q, Shi X F, Liu Y G, et al. 2007. Study on geochemical province of bottom sediment elements from south branch of the Changjiang River estuary. Advances in Marine Science, 25(4): 408-418. ]

王建, 刘泽纯, 姜文英, 等. 1996. 磁化率与粒度、矿物的关系 及其古环境意义 [J]. 地理学报, 51(2): 155-163. [Wang J, Liu Z C, Jiang W Y, et al. 1996. A relationship between susceptibility and grain-size and minerals, and their paleoenvironmental implications. Acta Geographica Sinica, 51 (2): 155-163. ]

王立伦, 王平, 苏珍, 等. 1989. 横断山冰川地球化学特征 [J]. 地理研究, 8(3): 66-77. [Wang L L, Wang P, Su Z, et al. 1989. Geochemical features of the glaciers in Hengduan Mountains. Geographical Research, 8(3): 66-77. ] 吴积善, 康志成, 田连权, 等. 1990. 云南蒋家沟泥石流观测 研究 [M]. 北京: 科学出版社. [Wu J S, Kang Z C, Tian L Q, et al. 1990. Observation and study on debris flow in Jiangjiagou, Yunnan. Beijing, China: Science Press. ]

徐树建, 丁新潮, 倪志超. 2014. 山东埠西黄土剖面沉积特征 及古气候环境意义 $[\mathrm{J}]$. 地理学报, 69(11): 1707-1717. [Xu S J, Ding X C, Ni Z C. 2014. The sedimentary characteristics of Buxi loess profile in Shandong Province and their paleoclimatic and palaeoenvironment significance. Acta Geographica Sinica, 69(11): 1707-1717. ]

袁方, 谢远云, 詹涛, 等. 2017. 地球化学组成揭示的杜蒙沙 地化学风化和沉积再循环特征及其对风尘物质贡献的 指示 [J]. 地理科学, 37(12): 1885-1893. [Yuan F, Xie Y Y, Zhan T, et al. 2017. Source-area weathering and recycled sediment for Dumeng sandy land inferred from geochemistry compositions: Implication for contribution to aeolian dust. Scientia Geographica Sinica, 37(12): 1885-1893. ]

张威, 柴乐. 2016. 他念他翁山中段第四纪冰川作用 ESR 定 年初步研究 [J]. 冰川冻土, 38(5): 1281-1291. [Zhang W, Chai L. 2016. The preliminary study of the Quaternary glacier in middle part of the Tenasserim Chain with ESR dating method. Journal of Glaciology and Geocryology, 38 (5): 1281-1291. ]

张威, 崔之久, 李永化. 2016. 青藏高原东缘第四纪冰川发育 特征与机制 [M]. 大连: 大连海事大学出版社. [Zhang W, Cui Z J, Li Y H. 2016. Characteristics and mechanism of Quaternary glaciers in the eastern margin of the Qinghai-Tibet Plateau. Dalian, China: Dalian Maritime University Press. ] 张威, 李媛媛, 冯䩀, 等. 2012. 青藏高原东缘山地古冰川沉
积物磁化率特点及其影响因素分析 [J]. 地理科学进展, 31(11): 1415-1425. [Zhang W, Li Y Y, Feng J, et al. 2012. Magnetic susceptibility of glacial deposits and the impacting factors in the eastern bordering mountains of the Tibetan Plateau. Progress in Geography, 31(11): 1415-1425. ]

张子洋, 间明, 刘连文, 等. 2017. 北极新奥尔松全新世冰碛 物物理化学特征及环境意义 [J]. 第四纪研究, 37(2): 293306. [Zhang Z Y, Yan M, Liu L W, et al. 2017. Physical and chemical characteristics of holocene moraines from NY-Alesund, Arctic and their environment implications. Quaternary Sciences, 37(2): 293-306. ]

Björck S, Dearing J A, Jonsson A. 2010. Magnetic susceptibility of Late Weichselian deposits in southeastern Sweden [J]. Boreas, 11(1): 99-111.

Dearing J A. 1994. Environmental magnetic susceptibility using the bartington MS2 system [M]. Kenilworth, UK: Chi Publishing: 52-55.

Dixon J B, Weed S B, Dinauer R C. 1989. Minerals in soil environments [J]. Soil Science, 150(2): 171.

Evans D J A, Owen L A, Roberts D. 2010. Stratigraphy and sedimentology of Devensian (Dimlington Stadial) glacial deposits, east Yorkshire, England [J]. Journal of Quaternary Science, 10(3): 241-265.

Krylov A A, Andreeva I A, Vogt C, et al. 2008. A shift in heavy and clay mineral provenance indicates a middle Miocene onset of a perennial sea ice cover in the Arctic Ocean [J]. Paleoceanography, 23(1): PA1S06, 1-10.

Jacobson A D, Blum J D, Walter L M. 2002. Reconciling the elemental and $\mathrm{Sr}$ isotope composition of Himalayan weathering fluxes: Insights from the carbonate geochemistry of stream waters $[\mathrm{J}]$. Geochimica et Cosmochimica Acta, 66 (19): 3417-3429.

Landim P M, Frakes L A. 1968. Distinction between tills and other diamictons based on textural characteristics [J]. Journal of Sedimentary Petrology, 38(4): 1213-1223.

Liu Z, Colin C, Li X, et al. 2010. Clay mineral distribution in surface sediments of the northeastern South China Sea and surrounding fluvial drainage basins: Source and transport [J]. Marine Geology, 277(1): 48-60.

Mclennan S M. 1993. Weathering and global denudation [J] Journal of Geology, 101(2): 295-303.

Nesbitt H W, Young G M. 1982. Early proterozoic climates and plate motions inferred from major element chemistry of lutites [J]. Nature, 299: 715-717.

Nesbitt H W, Young G M. 1984. Prediction of some weathering trends of plutonic and volcanic rocks based on thermodynamic and kinetic considerations [J]. Geochimica et Cosmochimica Acta, 48(7): 1523-1534.

Nordt L C, Driese S D. 2010. New weathering index improves 
paleorainfall estimates from vertisols [J]. Geology, 38(5): 407-410

Proust D, Eymery J P, Beaufort D. 1986. Supergene vermiculitization of a magnesian chlorite: Iron and magnesium removal processes [J]. Clays \& Clay Miner, 34(5): 572-580.

Sheldon N D, Tabor N J. 2009. Quantitative paleoenvironmental and paleoclimatic reconstruction using paleosols [J]. Earth Science Reviews, 95(1): 1-52.

Varga A, Újvári G, Raucsik B. 2011. Tectonic versus climatic control on the evolution of a loess-paleosol sequence at Beremend, Hungary: An integrated approach based on paleoecological, clay mineralogical, and geochemical data
[J]. Quaternary International, 240(1-2): 71-86.

Wang Q, Yang S. 2013. Clay mineralogy indicates the Holocene monsoon climate in the Changjiang (Yangtze River) Catchment, China [J]. Applied Clay Science, 74(3): 28-36.

Wentworth C K, Chester K.1922. A scale of grade and class terms for clastic sediments [J]. Journal of Geology, 30(5): 377-392.

Zhao X, Zheng B, Qin Y, et al. 2010. Grain size effect on $\mathrm{PBDE}$ and $\mathrm{PCB}$ concentrations in sediments from the intertidal zone of Bohai Bay, China [J]. Chemosphere, 81(8): 1022-1026.

\title{
Spatiotemporal characteristics and the environment of Quaternary glacier deposits in the middle Tenasserim Chain
}

\author{
ZHANG Wei, TANG Qianyu \\ (College of Urban and Environmental Sciences, Liaoning Normal University, Dalian 116029, Liaoning, China)
}

\begin{abstract}
Vestige of the Quaternary glaciation is well preserved in the middle Tenasserim Chain located in the west of the Hengduan Mountains. In this study, we investigated Quaternary glacial deposits in this area using the methods of luminescence dating, grain size, magnetic susceptibility, and mineral and chemical elements analyses, discussing the characteristics of sedimentology, mineralogy, environmental magnetism, and element geochemistry aspects of Quaternary glacial deposits during different periods in the study area. We also combined the related environmental indicators to analyze the environmental characteristics of this area. The results display that: 1) The overall sedimentary characteristics of glacial sediments are mixed size, no bedding, no sorting, and the degree of weathering weakened from the MIS6 to the MIS1. 2) Fine particles of glacial deposits in the study area show bimodal and multimodal spectra in frequency curves, which reflects that glacial deposits have complex sources. The average grain size of moraines shows that the farther away from the source of glaciation, the smaller the grain size-it was mainly affected by the intensity of glaciation and the duration of weathering. 3) The magnetic susceptibility of glacial deposits in the study area ranges from $8.72 \times 10^{-8} \mathrm{~m}^{3} \cdot \mathrm{kg}^{-1}$ to $298.00 \times 10^{-8} \mathrm{~m}^{3}$. $\mathrm{kg}^{-1}$. The average value $\left(178.51 \times 10^{-8} \mathrm{~m}^{3} \cdot \mathrm{kg}^{-1}\right)$ and amplitude of fluctuation $\left(17.43 \times 10^{-8}-298.00 \times 10^{-8} \mathrm{~m}^{3} \cdot \mathrm{kg}^{-1}\right) \mathrm{of}^{-}$ the magnetic susceptibility of ice water deposits are greater than moraines (average value: $19.82 \times 10^{-8} \mathrm{~m}^{3} \cdot \mathrm{kg}^{-1}$, amplitude of fluctuation: $8.72 \times 10^{-8}-42.95 \times 10^{-8} \mathrm{~m}^{3} \cdot \mathrm{kg}^{-1}$ ), which reflects that the grain size of centralized distribution of magnetite is similar to the grain size of ice water deposits. 4) The analysis of geochemical indicators of elements and minerals show that the overall characteristics of the paleoclimate in the Qinggulong area was cold and dry; the climate was the driest during the MIS2, but precipitation of the MIS3b was higher. The precipitation of MIS6 was more than the MIS2 and MIS3b, but the temperature was lower.
\end{abstract}

Keywords: luminescence dating; grain size; magnetic susceptibility; chemical element; mineral; glacier deposits; the middle Tenasserim Chain 